\title{
THE PROJECT METHOD AS A TOOL OF EFFECTIVE TEACHING A FOREIGN LANGUAGE IN DISTANT AND MIXED LEARNIN
}

\author{
Iuliia Didkivska \\ Lecturer at the Department of Foreign Philology and Translation, \\ Kyiv National University of Trade and Economics, Ukraine \\ e-mail: i.didkivsk@knute.edu.ua,orcid.org/0000-0002-6346-7105
}

\section{Summary}

The aim of this paper is to prove the hypothesis that the application of project methods in foreign language lessons shows that students achieve good results in learning a foreign language, have a practical opportunity to apply the skills acquired in computer science lessons. The main advantages of the project method are: increasing the motivation of students in learning English, visual integration of knowledge in different subjects, space for creative activity. A project is an opportunity for students to express their own ideas in a creative form that is convenient for them: making collages, announcements, conducting interviews and research etc. The most important thing is that the child, not the teacher, determines what the project will contain, in what form and how it will be presented. Achieving the goal of the project is subject to all actions developed by students and teachers: the study of the necessary lexical and grammatical units, search for sources of information, selection of the necessary information, design and presentation of results. In teaching foreign languages, the project method allows students to use the language in real-life situations, which contributes to better learning and consolidation of foreign language skills. Methods used in the study: general scientific (analysis and synthesis, induction and deduction), methods of theoretical research (from abstract to concrete), historical method.

Keywords: motivation, visual integration, creative activity, consolidation of foreign language skills.

DOI: https://doi.org/10.23856/4703

\section{Introduction}

The combination of traditional and innovative methods in foreign language teaching allows to improve the quality of education, provides psychological and emotional comfort, expands opportunities in the formation of communicative competence, self-education and selfrealization of each student. It contributes to the quality of students' mastery of all types of speech activities: reading, speaking, writing, listening and develops skills of independent and joint activities within the educational process.

Modern pedagogy is aimed not only at the formation of a comprehensive and harmonious personality, ultimately would be able to build their own life, and the initiation of growth of personal qualities, the development of individual and unique in man, that is, the function of the individual is not reduced to the direct consumption of the proposed product, and allows the formation of subjective evaluation (Voronin, Saienko \& Tolchieva, 2020: 758). Let us turn to the history of the creation and reflection of the pedagogy of project activity itself. American scientists John Dewey and William Hurd Kilpatrick are considered to be the founders of the 
project methodology. The idea of project-based learning has a long scientific tradition, is in an equally traditional opposition to type teaching (Beckett \& Slater, 2018: 6).

Pedagogical project is an organizational form of pedagogical activity aimed at mastering the didactic unit, forms the readiness to solve the socially significant problem. "The project method is precisely a difficult educational method, one of the active methods of conducting classes, contributes to the individualization of the educational process, provides a guaranteed achievement of the planned result ensures independence in the planning, organization and revision of its activities"(Wicke, 2004: 29).

The organizational form is implemented mainly in individual, pair or group activities of students. Project activity, forms communicative competence, in the teaching of foreign languages it is a relatively new technique, mainly focused on the creation by participants of education their own intellectual product causes some didactic problems (Golonka et. al., 2014: 85).

The results of the project are not always predictable, they require considerable effort, but in turn allows students to be independent in choosing sources of information, methods of presentation and presentation, as well as to conduct individual work on the topic of most interest to each project participant, causing increased motivated student activity

\section{Purpose and objectives}

The purpose of educational design is to create such conditions for the teacher during the educational process, in which the result is the individual experience of the student's project activities.

Productive activity, first of all, fruitful for education, is an individual action, the result of which can be a useful material or intangible product, therefore, it has practical value. As such learning develops in productive activity, it expands the scope of subjectivity in the process of self-determination, creativity and concrete participation. When using technology, a number of different levels of didactic, educational and developmental tasks are solved: students' cognitive skills are developed, the ability to independently construct their knowledge is formed, the ability to navigate in the information space, critical thinking, communication and more are actively developed.

The purpose of the project is to promote the formation of a system of knowledge and skills embodied in the final intellectual product, to promote independence, the ability to think logically, see problems and make decisions, receive and use information, plan, develop literacy and more.

The main features of the educational project: the presence of a problem; subject integration; independent activity of students; product - the result of a project created by students; product presentation.

Project work is extremely important because it combines all language skills and motivates students who have the opportunity to work at their own level and according to their hobbies, as well as to present the results of their work to the group in the form of a presentation (Lin et. al, 2021). This creative task can be both individual and group, so it is organically combined with a group approach to learning. The project method is always focused on the independent activities of students, which must be completed within a certain period. The method of projects always involves solving a problem, which involves, on the one hand, the use of various methods, teaching aids, and on the other hand, the integration of knowledge, skills from different fields of science, technology, creative areas.

When applying the project method, the initial stage is planning and preparation for its implementation. The teacher needs to develop a plan of project work and think of a system of communicative exercises that will provide its language level. Students should be fluent in active 
vocabulary and grammar within the educational topic before proceeding to the discussion of problematic issues (Oliynyk, 2012: 14).

After preparation comes the longest stage of work on the project - is the collection of information, the search for new knowledge, the formation of personal opinion and view on the subject of design. This is where the main work of an English teacher with his students takes place, intermediate results are discussed, mistakes in the use of language units are corrected. Work of this kind provides a large number of opportunities to use the passed grammatical phenomena and structures (Oliynyk, 2012: 14). Maintaining a welcoming atmosphere is an important prerequisite for effective project work. The third stage of the project work involves students working on the technical implementation of the project.

The advantages of the project method are: development of skills of self-education and self-control; development of group activity skills; development of information handling skills (search, analysis, systematization, selection of key positions, formation and presentation) creative development; increasing motivation and information culture; integration of knowledge in different subjects;

The disadvantages of project activities include: the problem of subjective evaluation of creative work; technical overlays that can affect both the work process and the end result (Oliynyk, 2012: 18).

Despite some shortcomings, project work fits best into the competency approach, which includes the development of three components in students:

- ability to work with different sources of information;

- ability to work in a group;

- ability to work independently (Redchenko, 2016).

So, the individualization of the learning process provides the project method gives the student the opportunity to be independent in planning, organizing and controlling their activities. The application of project methodology in the classroom provides support for a lasting interest in learning a foreign language, deepens and systematizes students' knowledge of the studied topic.

The main tasks:

1. Provide independent acquisition of knowledge, the ability to apply it to solve new cognitive and practical problems, not just the actual transfer of this or that amount of information.

2. Assist the student in acquiring communication skills, ie the ability to work in different groups, performing various social roles (leader, performer, mediator, etc.), to expand the circle of communication of children, acquaintance with other cultures, different points of view on one problem.

3. To instill in students the ability to use research techniques: necessary, analyze information, clearly formulate judgments and form hypotheses, organize data, and summarize results.

The main goals of foreign language teaching are the formation and development of students' communicative competencies and their application in practice in new real situations. Project activities contribute to the realization of these goals. It allows you to create a creative atmosphere in the classroom, where each student is involved in an active cognitive process based on the methods of cooperation. The project is an opportunity for students to express their own thoughts and ideas in a creative form that is convenient for them. Working on a project gives students the opportunity to reflect, independently search, analyze and summarize the necessary information. They independently transfer previously acquired knowledge, skills and abilities into a real situation. 


\section{Types of projects}

Any project activity is carried out in several stages, a common literature is the following typology of projects: research projects, creative projects, game projects, information projects, practice-oriented projects.

Research projects - require a well-thought-out structure, a defined goal, the relevance of the subject of research for all participants, social significance, thoughtful methods, including experimental methods of processing results. They are completely subordinated to the logic of research and have an appropriate structure: defining the research topic, arguing its relevance, defining the subject and object, tasks and methods, defining research methodology, hypotheses for solving the problem and outlining ways to solve it.

Creative projects - do not have a detailed structure of joint activities of participants, it develops, subject to the end result, the group adopted the logic of joint activities, the interests of project participants. They agree in advance on the planned results and the form of their presentation - handwritten magazine, collective collage, video, evening, holiday, etc. And then you need a movie script, a holiday program, a layout of a magazine, an album, a newspaper.

Game projects - participants take on certain roles due to the nature and content of the project. Projects in which participants take on certain roles through the nature and content of the project are called playful. For example, imitation of social and business relationships, through playing the roles of both literary characters and real-life personalities, are complicated by fictional situations.

Projects aimed at familiarizing project participants with information, its analysis and synthesis of facts, collecting about a phenomenon or objectare called information projects. The requirements for such projects are clearly planned and thought-out stages with the possibility of correction at any stage. Describing practically oriented projects, it is worth noting that in the case of testing this method, the result of the participants' activities is clearly defined from the beginning, and focused on the social interests of participants (document, recommendation, bill, dictionary, project).

The project requires a scenario of all activities of its participants with the definition of the functions of each of them. Especially important is the good organization of coordination work in the form of step-by-step discussions and presentation of the obtained results and possible means of their implementation in practice.

According to the nature of contacts, projects are divided into domestic and international. Internal projects are projects organized either within one school or between schools, classes within the region, the country. Representatives of different countries take part in international projects, and information technology tools can be used for their implementation.

According to the number of participants, projects are divided into individual, pair and group. According to the duration of the projects, there are short-term (several lessons from the program of one subject), medium duration (from a week to a month), long-term (several months). In practice, more often we have to deal with mixed types of projects. It is very important to organize an external evaluation of the project, which allows to increase the efficiency of its implementation, eliminate difficulties, make timely corrections. In game projects that have the nature of competition, a scoring system can be used. It is difficult to evaluate intermediate results in creative projects. But monitoring is still necessary to help when needed. 


\section{Requirements for the teacher's personality}

The most appropriate for the implementation of the goals of teaching foreign languages are interdisciplinary, group, medium-term, research, information and practice-oriented projects, which are characterized by open, flexible coordination, both external and internal contacts (Adnan, 2018:89).

The ability to use project technology is an indicator of high qualification of the teacher, his innovative thinking, and focus on personal and professional development of the child in the learning process.

The functions of the teacher in the organization of instructional design are as follows (Kacetl \& Klímová, 2019):

- assists students in finding the sources they need to work on the project;

- it is a source of information;

- coordinates the whole process of working on the project;

- supports and encourages students;

- supports the continuous movement of students in working on the project. You need to be able to help the student without doing work for him.

The teacher must not only know his subject well, but also be competent in other fields of science, to see the points of their collision.

Psychological literacy and competence of the teacher are extremely important for the organization of project activities of students. The teacher must be communicative, tolerant (Sergeeva, 2014). A special role is played by the creative abilities of the teacher, the experience of creative activity creative potential in general. The teacher influences students with the brightness of their own individuality. Self-esteem is as important in this technology as in any other.

\section{Conclusions}

Analyzing the presented practical experience of project development, we note that the idea of project-based learning is focused on the formation of students' deep knowledge, creativity and creative thinking, the formation of activity in solving professional and practical problems by means of a foreign language. Project technology provides the use of research, search, problem methods, and allows you to simulate the full cycle of thinking - from the origin of the problem situation, the formation of cognitive motivation to find ways to solve problems, evidence of the solution and implementation of the results. The use of project methods in the practical teaching of a foreign language makes it possible to create a specific language environment, as a native speaker participant can take part in the projects. The use of project methods in practical foreign language teaching ultimately requires a good language base, but also less prepared participants are also able to prepare a project if they maintain a clear structure and if they become more complex. It is necessary to formulate the tasks in such a way as to orient to the involvement of facts from meaningful areas of knowledge and a variety of sources of information. Today, we understand the phrase "project method" and a certain set of ideas, and a fairly clear pedagogical technology, and specific practice of teachers. In order for teaching to be effective, it must be interesting not only for students, but also for the teacher himself, who must enjoy learning his subject and teaching it. No one claims that project work will help solve all learning problems, but it is an effective remedy for boredom. It promotes the development of students, self-awareness as a member of the group, the expansion of language skills. The project is also a real opportunity to use the knowledge gained in other lessons of foreign languages. 


\section{References}

1. Adnan, M. (2018). Professional development in the transition to online teaching: The voice of entrant online instructors. ReCALL, 30(1), 88-111.

2. Beckett, G. H., \& Slater, T. (2018). Project-based learning and technology. The TESOL encyclopedia of English language teaching, 1-7.

3. Golonka, E. M., Bowles, A. R., Frank, V. M., Richardson, D. L., \& Freynik, S. (2014). Technologies for foreign language learning: A review of technology types and their effectiveness. Computer assisted language learning, 27(1), 70-105.

4. Kacetl, J., \& Klímová, B. (2019). Use of smartphone applications in english language learning - A challenge for foreign language education. Education Sciences, 9(3), 179.

5. Lin, K. Y., Wu, Y. T., Hsu, Y. T., \& Williams, P. J. (2021). Effects of infusing the engineering design process into STEM project-based learning to develop preservice technology teachers ' engineering design thinking. International Journal of STEM Education, 8(1), 1-15.

6. Oliynyk, I. P. (2012). Vykorystannia metodu proektu na urokakh anhliiskoi movy yak odyn iz sposobiv formuvannia komunikatyvnoi kompetentnosti uchnia [Using the project method in English lessons as one ofways to form the communicative competence of the student]. Kotovsk 21 p. [in Ukrainian]

7. Redchenko, N. N. (2016). Project Activities as a Form of English Language Teaching Based on the Interdisciplinary Approach to Form Intercultural Communicative Competence. International journal of environmental and science education, 11(13), 6203-6211.

8. Sergeeva, N. N. (2014). Foreign language communicative competence in the field of professional activity: Model and method development. Procedia-Social and Behavioral Sciences, 154, 250-253. 9. Voronin, D. M., Saienko, V. G., \& Tolchieva, H. V. (2020, May). Digital transformation of pedagogical education at the university. In Proceedings of the International Scientific Conference "Digitalization of Education: History, Trends and Prospects"(DETP 2020) (No. 437, pp. 757-763). 10. Wicke, R. E. (2004). Aktiv und kreativ lernen Projektorientierende Spracharbeit im Unterricht. Hueberverlag, - Ismaning - 2008. 